\title{
"Perspectives on Coping and Resilience" - A Critical Essay
}

\author{
Rachel Mitchell1 ${ }^{1}$
}

\begin{abstract}
:
Literature examining concepts of coping and resilience within a range of diverse fields such as social work, psychology, art, spirituality and management science, have emerged and have shifted a focus from sustainable practices to resilience building. A recently released book, Perspectives on Coping and Resilience "examines the interplay of individual, family, community and social factors, and deepens our understanding of the human ability to 'bounce back' - a vital competency for success" (Pulla, Shatte \& Warren, 2013). Perspectives on Coping and Resilience brings together the above mentioned disciplines and their relevance within individual, group and community resilience building. This paper will review and build upon the writings of Pulla, Shatte and Warren (2013) and a variety of extended authors whilst highlighting key areas of children and emotional stability, gender issues, trauma and violence.
\end{abstract}

Keywords: Coping, Resilience, Social Work, Human Services, Emotional Stability, Bouncing Back, Strengths Approach

\section{Introduction:}

Pulla, Shatte \& Warren (2013, pp. 12-13) clearly link the resilience of an individual, group or system to its ability to interact with and adapt to the present environment, along with the production of strengths to cope with the stress and adversity experienced within a crisis. This ability to 'bounce back' - in biological, psychological and social terms - relies on an understanding of risk factors which have the ability to hinder successful adaptation and maintenance of typical functioning within changing circumstances and environments (Wu, Feder \& Mathe, 2013). A need for such resilience is a basic human right (Pulla, Shatte \& Warren, p. viii,) which calls for greater resilience building efforts across a range of disciplines, including social work, psychology and management science. Perspectives on Coping and Resilience (Pulla, Shatte \& Warren) brings together relevant findings on resilience and resilience building, across a range of disciplines and levels of society. The text highlights areas of children and emotional stability, gender issues, trauma and violence and their relevance to coping and resilience, with reference to the strengths perspective. The 24 contributors to this text have also given weight within specific chapters to national and organisational resilience, addiction and co-dependence, art therapy and arts practice, spirituality and young people with disabilities.

Pulla, in Perspectives on Coping and Resilience distinguishes between and categorises coping strategies as cognitive-focussed, appraisal-focussed and emotions focussed (Pulla, Shatte \& Warren, 2013, p. 7) and distinguishes between effective and maladaptive coping strategies. Maladaptive coping strategies are those which appear effective and successful in the short-term, but fail as long-term coping techniques (pp. 9-10), and have the ability to hinder the development of resilience as it creates a false sense of adaptability and success.

Resilience is framed as not only impacting upon macro and meso levels of society, but is rooted within "our beliefs and values, in our character, experiences, values and genes (and influenced by and influencing of) our habits of mind - habits we can cultivate and change" (Zolli, 2012, p. 14). These factors have the ability to create an environment in which resilience may be built, alongside cooperative and trusting surroundings, strong communities and leadership and structural adaptability (p. 15). The ability for communities and organisations to remain dynamic and adaptable ensures openness to reconfiguration, and in turn, allows a degree of coping and resilience. Resilience implies that an individual, group or community will recover from trauma and crisis, display competence and obtain reasonable outcomes, whilst using these adversities for growth (p. 15). Emotional responses occur within the cognitive, behavioural, and neurophysiological and biochemical levels of an individual (Warren in Pulla, Shatte \& Warren, 2013, p. 392) and regulation across these levels results in the ability to "control the urges to engage in impulsive behaviours, such as self-harm, recklessness, or physical aggression, during emotional distress" (p. 388).

\footnotetext{
${ }_{1}^{1}$ Rachel Mitchell is studying Bachelors degree in Social Work at the School of Humanities and Social Sciences, Charles Sturt University, Wagga Wagga, Australia. Email: rach.mitchell@hotmail.com
} 
Hudson and Pulla define emotional regulation and the common characteristics portrayed in children who demonstrate resilience, and the context in which children may develop this. For example, having a high tolerance to distress, secure attachments and social supports - including a sensitive and responsive carer who is familiar with the specific needs of the child and provides a stable, safe and predictable environment where emotional communication is encouraged. A child having opportunities to grow and learn gradually through practice of processing distress and having a stable emotional environment to return to, adequate financial resources, appropriate neurological and emotional development and a carers appropriate self-regulation are all positive environmental factors said to frame resilience within an individual child (pp. 17, $103 \& 116$ ). This emotional regulation allows the child to respond flexibly and in a socially appropriate manner in an array of differing environmental changes - "allowing for spontaneity as well as being able to inhibit behaviour" (Pulla, Shatte \& Warren, 2013, p. 101). The most common characteristics Luthar (2006) found within resilient children were "good cognitive ability....and temperaments that facilitate good social relationships". Luthar's findings were not so much around the actual available resources to the child, but the individual's personal characteristics and attributes. Whilst the circumstantial characteristics may not be evident within children who are exposed to forced displacement, Betancourt and Khan (in Siriwardhana \& Stewart, 2013) reported that these children may "fare better on long term outcomes", due to the resilience developed through adverse circumstances in childhood. It has been found that approximately a third of children who are subject to abusive environments "grow into healthy and capable adults, demonstrating remarkable resiliency" (Orbke \& Smith, 2002).

The concept of resilience is linked to emotional regulation through a process of developing "the ability to bounce back and respond flexibly to situations" (Pulla, Shatte \& Warren, 2013, p. 116) and managing intense emotions through fostering the use of internal and external resources to develop adaptation, coping and self-regulation skills (White \& Pulla in Pulla, Shatte \& Warren, 2013, p. 123). Such resilience building is seen as a collective responsibility with schools, families and communities are key relationships within this (p. 126) and should be facilitated within the micro, meso, exo and macro systems of each child - both individually and collectively (p. 128). Interventions may be child, family, community, school or society based and White \& Pulla identify key elements of each of these interventions (pp. 132-144). Specific and practical step-by-step strategies such as cognitive awareness have been outlined, for example a stop and evaluate approach to overcoming impulsive emotional responses and an internal control approach (Warren in Pulla, Shatte \& Warren, 2013, p. 395).

A recent study found that whilst throughout their lifetime, 50-60\% of participants experienced severe trauma, Post Traumatic Stress Disorder was only estimated to affect $7.8 \%$ of individuals (Russo, Murrough, Han, Charney \& Nestler, 2012). On the other hand, $\mathrm{Wu}$, Fender \& Mathe (2013) have stated that severe adverse childhood events may create long term developmental damage to areas of the brain associated with mood disorders and stress response. Douglas (in Pulla, Shatte \& Warren) writes concerning brain function and neural pathways with both victims of domestic violence and child abuse, and the long term effects that these have on an individual's brain and ability to respond appropriately both emotionally and socially (pp. 203-205). Douglas distinctly links resiliency in such scenarios to being "the survivor's ability to find a means of surviving the emotions" (p. 206), even if these coping mechanisms are maladaptive. Again, secure attachments and supportive relationships are seen to be linked closely with individual resiliency within abusive situations. Douglas states that "(r)ecovery can take place only within the context of relationships; it cannot occur in isolation" (p. 208), and is based within the creation of new or renewed relationships. Trotman \& Townson (in Pulla, Shatte \& Warren) also outline the mirror neuron system and the social meaning of behaviour, actions, intentions and emotions (p. 288).

In Wu, Fender \& Mathe's study, “(c)hildren with a history of maltreatment showed lower resilient functioning to those without maltreatment", with protective measures stated ashaving a secure attachment to their carer, accessible social supports, positive religious meanings within suffering, shared values and a sense of humour (Wu, Fender \& Mathe, 2013; Orbke \& Smith, 2013). It has been reported that "emotional support and encouragement offered by significant adults in a child's life are crucial for promoting self-wroth and resilience" (Brooks, 1994, p. 551). Conversely, a child's resilience is commonly affected by a carer's maltreatment through abuse, neglect, family conflict or parental mental illness (Orbke \& Smith, 2012). It has been reported that a factor influencing whether or not a child's traumatic experience leads to resilience, as opposed to vulnerability, is the individual's sense of control over the stressor (Wu, Fender \& Mathe, 2013). A learned helplessness, "where a person is conditioned to believe that they are unable to change the circumstances of their situation" (Wu, Fender \& Mathe), leads to an individual's vulnerability, whilst an individual mastering a stressor through an adaptive stress response tends to lead to higher levels of resiliency.

The "Yangarger-Hick's study (2004) of individuals diagnosed with serious mental illness revealed that those who lent more importance to religion also reported greater feelings of empowerments as long as they were not "waiting for God to solve problems and asking for a miracle." However, working with God towards recovery was associated with greater 
(individual) empowerment" (Douglas in Pulla, Shatte \& Warren, p. 212). Spirituality and a relationship with God was also claimed to assist in meaning making of abuse (p. 211) and the creation of hope.

Zhou \& Landa's chapter "Life Narratives Mirroring the Feminization of HIV and AIDS Trauma: Zimbabwean Perspectives on Coping and Resilience" (in Pulla, Shatte \& Warren, 2013, pp. 399-418) provides valued insight into the experience of HIV, AIDS and gendered violence in Zimbabwe and the coping mechanisms commonly utilised. The ability to cope successfully has been said to be "determined by the efficacy of culturally-provided solutions to such stressful situations" (p. 408). Coping strategies of silence and secrecy are shown to be maladaptive, however are culturally acceptable as women who vocalise "unspeakable and taboo subjects" - such as domestic violence - are "branded as a disgrace to (their) clan" (p. 409). De-silencing has been described as an empowering mechanism for women and whilst being "against the prohibitive cultural and traditional practices that keep women in bondage" (p. 411), anecdotal accounts show of the liberation which comes as using de-silencing as the woman "realizes that the fear of the public and carrying a secret is more suffocating than living in the open and having no secret logged onto one's heart" (p. 413). However, many women, Zhou \& Landa state, are fearful of being thrown out of their homes, abandoned, socially ostracised, disgraced or creating further domestic upheaval (pp. 409-410), forcing them to remain in silence.

Due to the universal implications within the writings of the text, Perspectives on Coping and Resilience is a valuable resource to a range of disciplines, such as social work, psychology, community development and management science. The text covers a broad range of topics and does not generally flow between each chapter, but rather, all contribute towards creating further insight into varying levels of coping and resilience. The anecdotes within many of the chapters and the varying frameworks used - such as art therapy and community resilience - give practical relevance to the philosophical approach used throughout the text and aid with reflection and models for implication.

Acknowledgment: This critical review is based on Pulla, V., Shatte, A. \& Warren, S. eds .,(2013). Perspectives on Coping and Resilience, New Delhi: Authorpress Global Network

ISBN 978-81-7273-715-3

\section{References}

Brooks, R. B. (1994). Children at risk: fostering resilience and hope. The American Journal of Orthopsychiatry, 64(4), 545-553

Luthar, S. S. (2006). Resilience in development: A synthesis of research across five decades. In D. C. Cicchetti (Ed.) Developmental psychopathology: risk, disorder and adaptation ( $2^{\text {nd }}$ ed., Vol 3, pp. 739-795). Hoboken: John Wiley and Sons.

Orbke, S., \& Smith, H. (2012). A Developmental Framework for Enhancing Resiliency in Adult Survivors of Childhood Abuse. International Journal for the Advancement of Counselling. 10.1007/s10447-012-9164-6

Pulla, V., Shatte, A., \& Warren, S. (2013). Perspectives on Coping and Resilience. Delhi: Authors Press.

Russo, S. J., Murrough, J. W., Han, M. H., Charney, D. S., \& Nestler, E. J. (2012). Neurobiology of resilience. National Neuroscience, $15,1475-1484$.

Siriwardhana, C., \& Stewart, R. (2013). Forced migration and mental health: prolonged internal displacement, return migration and resilience. International Health, 5(1), 19-23.

Wu, G., Feder, A., \& Mathe, A. A. (2013). Understanding resilience. Frontiers in Behavioral Neuroscience, 7, $1662-5153$.

Zolli, A. (2012). Resilience: Why things bounce back. New York: Free Press. 